\title{
A LDB E AS INSTITUIÇÕES DE EDUCAÇÃo INFANTIL: DESAFIOS E PERSPECTIVAS ${ }^{1}$
}

\author{
Tizuko Morchida KISHIMOTO*
}

\begin{abstract}
A Educação infantil, primeira etapa da educação básica, tem como finalidade o desenvolvimento integral da criança até seis anos de idade, em seus aspectos fisico, psicológico, intelectual e social, complementando a ação da família e da comunidade (art.2. $L D B)$.
\end{abstract}

Se a legislação propõe o desenvolvimento integrado da criança como objetivo a alcançar, como afirmar que na sala de aula se aprende e no pátio se recreia? Qual a participação do corpo e do movimento na educação? A fragmentação e compartimentalização de aspectos do desenvolvimento infantil (físico, intelectual, psicológico, social) espelham-se nas concepções dos profissionais, na organização do espaço físico, materiais e práticas pedagógicas. $\mathrm{Na}$ sala de aula ocorre o desenvolvimento intelectual e psicológico, no pátio, o físico e social.

Como justificar o controle do corpo, salas de aulas $e$ atividades concebidas na perspectiva do adulto, em que não há espaço para ações autônomas da criança? Os materiais mais presentes, são os gráficos, que não privilegiam o corpo e o movimento. As práticas pedagógicas atribuem maior tempo para atividades intelectuais voltadas para aquisição das letras e números. Brinquedos e brincadeiras aparecem no discurso, mas na prática restringem-se ao recreio e momentos de transgressão das normas.

O trabalho com a família e a comunidade não pode ser ocasional, mas complementar do pedagógico para desenvolver a criança integralmente. Como isso é possível em agrupamentos infantis que chegam a ter 30 a 40 crianças, com profissionais sem formação, tempo e materiais?

$\mathrm{Na}$ base desses problemas encontram-se concepções de criança e de educação, fatores de ordem conjuntural e inadequação de processos de formação que precisam ser explicitados.

Um dos grandes desafios é ultrapassar a retórica da infância (Becchi \& Julia, 1998), slogans e modismos, aprender a olhar a criança e dar-lhe espaço de expressão. A valorização da infância como categoria social, apesar de presente no discurso, não encontra espaço no cotidiano infantil.

A criança concebida como ser humano em desenvolvimento, dotado de competências, saberes e direitos, situada em um contexto histórico e social, contrapõe-se às experiências de exclusão, que separa crianças pobres e ricas, meninos de rua, crianças com famílias de outras abandonadas, exploradas e violentadas (Pinto \& Sarmento, 1997).

Valorizar a identidade de cada criança exige reflexão sobre sua identidade e como construí-la (Haddad, 1991). Essa é uma das indicações das Diretrizes Curriculares da Educação Infantil, aprovada em 1999, que constitui um desafio.

As creches e pré-escolas existentes ou que venham a ser criadas deverão, no prazo de três anos, a contar da publicação desta Lei, integrar-se ao respectivo sistema de ensino (LDB, Título IX, Das Disposições Transitórias, art. 89). Tal determinação desnudou concepções, práticas e políticas públicas.

Não basta transferir creches para o âmbito da educação. Outros aspectos precisam ser considerados: concepções de criança e de educação, níveis de formação e funções dos profissionais, diferenças salariais, estrutura e funcionamento dos equipamentos infantis, financiamento, formação.

Muitos privilegiam o educar e o cuidar apenas na dimensão pedagógica. É

\footnotetext{
'Faculdade de Educação da Universidade de São Paulo.
} 
necessário concebê-los em perspectiva mais ampla, de um desenvolvimento que se processa num plano, como diria Bronfrenbrenner (1996), ecológico, em vários níveis que se relacionam. Desde o berçário, em todas ações do cotidiano, é preciso integrar ações de cuidado e educação. Outras formas de integração: pré-escola e ensino fundamental, creche e família, creche e pré-escola. Estruturas contínuas possibilitam melhor atendimento à criança

$$
\text { Integrar significa centralizar e }
$$

aproximar serviços, buscando acomodaçōes, reconciliações e ajustamentos. Para o Programa Early Excellence Centre, uma política governamental valoriza a integração, quando há investimentos em todos os setores educacionais e sociais, nutrição, saúde, competências familiares, igualdade de oportunidades de acesso e formação, respeito aos problemas de gênero incluindo educadores do sexo masculino e correspondente valorização da profissão, cuidado e desenvolvimento de recursos humanos e atenção para as potencialidades das crianças (Pascal, Bertram, Gasper, Mould, Ransden \& Saunder, 1999, p.11-3).

A construção da proposta pedagógica é o aspecto mais relevante da dimensão cuidareducar. Conceber um projeto pedagógico não é tarefa solitária do profissional encerrado nas quatro paredes de sua sala. Não é um documento exógeno que deve ser aplicado pela instituição. É fruto de trabalho coletivo, de todos os profissionais, equipe da escola, gestores, pais e comunidade. Essa tarefa demanda um diagnóstico da realidade escolar, a identificação do sujeito da educação, de concepções sobre a educação que se deseja oferecer, a definição e detalhamento de ações, a curto, médio e longo prazos, a seleção e organização dos recursos humanos e materiais. A avaliação deve acompanhar todas as etapas do trabalho. Não a avaliação de resultados, mas a avaliação do processo de trabalho, na acepção de Perrenoud (1999), que parte dos interesses, necessidades, saberes e competências das crianças. Avalia-se não só o percurso da criança, mas o caminhar da equipe, contemplando acertos e desacertos em busca das metas traçadas.

Em tempos passados, concepções de criança e educação propunham retirar as crianças das ruas para encerrá-las entre quatro paredes, com cuidados mínimos de saúde, higiene, alimentação e vigilância total (Foucault 1977). Hoje, reproduzem-se quadros similares: disciplinar por meio de orações e tempo de espera, exercícios gráficos e conteúdos escolares, atividades fragmentadas ou pouco relevantes para a educação e o desenvolvimento infantil.

Como no ensino fundamental, há filas para entrar, carteiras alinhadas, nucas atrás de nucas, mesinhas de quatro a seis lugares, onde apenas a proximidade física une as crianças. Não há cooperação, expressão de necessidades individuais e coletivas. Prevalecem atividades iguais para todas as crianças, contrariando as propostas de autonomia, expressão e identidade infantis.

O espaço para aprender é restrito à sala de atividades, decorrente das concepções de educação (Nóvoa, 1992). O ambiente de aprendizagem deve abranger todo o contexto, avançar nos espaços públicos e privados, envolvendo pais, comunidade e outros agentes, $o$ que parece não ocorrer.

$\mathrm{Na}$ interação adulto-criança prevalece a visão adultocêntrica. Não se valoriza a aprendizagem decorrente das relações entre crianças de diferentes idades, de adultos de diversos meios, espontânea, construída pelas próprias crianças em contato com seu meio, com objetos e situações diversas. Grandes agrupamentos, com muitas crianças, inviabilizam o trabalho com qualidade. Em decorrência, os profissionais estão sempre muito ocupados, dirigindo as atividades, distribuindo materiais, chamando a atenção das crianças, não dispondo de tempo para observar ou interagir com elas.

É necessário pensar em formas de organização do tempo e do espaço, que evitem a rotinização (Barbosa, 2000), que contemplem momentos individuais, em grupo, que valorizem ora a ação livre e deliberada da criança, ora a orientação do profisssional, que incluam espaços internos e externos, o contato com múltiplos personagens da instituição, da família e da comunidade.

O modelo de escolarização, hegemônico, expande suas ramificações nos cursos de formação de professores, em nível superior, Pedagogia e, em nível médio, habilitação de Magistério, com um currículo de orientação disciplinar carregado de metodologias para o ensino de Português, Matemática, Ciências, História, Geografia, Educação Física e Artes (Kishimoto, 1999). As creches, destinadas a crianças de zero a três anos ou até seis anos, reproduzem, em sua grande maioria, a perspectiva assistencialista, de maternagem (Rayna \& Brougère, 2000). A falta de especificidade da 
educação da criança continua nas formas de gestão, em que um mesmo supervisor é responsável pela faixa etária de zero a dez anos.

A cultura que prevalece nas escolas infantis (Forquin, 1996) reflete valores cristalizados nos modelos de escolarização. ${ }^{2}$ A desigualdade social e econômica trouxe a ansiedade na população em busca da ascensão social via escolarização, ocasionando a aceleração do aprendizado já na fase infantil. Nessa busca esquece-se a criança, sua forma específica de aprendizagem e desenvolvimento. Toma-se a criança como pequeno adulto, com potencialidades para crescer rápido e aprender ainda mais depressa. Escolas infantis repletas de materiais gráficos e computadores evidenciam essa pressa. A entrada no mundo tecnológico, o domínio dos processos informatizados, antes mesmo da construção de processos de representação do mundo da criança, acaba invalidando o esforço para desenvolver a criança. Antes da palavra escrita, ocorre a representação, que é simbólica, motora, expressiva. É preciso respeitar as características do desenvolvimento infantil. $O$ letramento e a aquisição da linguagem requerem a construção de representações mentais, de significações para os códigos escritos. Não é pelo ensino mecânico de símbolos escritos que se chega à linguagem. É preciso que a atividade simbólica, responsável pelas representações construídas nas brincadeiras e atividades, seja experimentada para que a criança possa construir sua linguagem.

Brincadeiras são formas de comunicação que permitem partilhar significados e conceber regras (Bateson, 1977; Bruner, 1996) para desenvolver e educar as crianças. Pelo brincar se pode compartilhar valores culturais e significações, expressar idéias, compartilhar emoções, aprender a tomar decisões, cooperar, socializar e utilizar a motricidade.

O direito à educação infantil não é respeitado não só pela taxa de demanda que, segundo o censo de 2000 , gira em torno de $54 \%$ para crianças de quatro a seis anos e $10 \%$ para as de zero a três anos. Na rede de educação infantil nos municípios de São Paulo e Grande São Paulo, as creches que atendiam crianças de zero a seis anos, em tempo integral, passam a oferecer, às de zero a três anos, período parcial ou integral; crianças de quatro a seis anos passam a ser atendidas prioritariamente em tempo parcial; as crianças de seis anos são absorvidas no ensino fundamental sem adequações no projeto pedagógico; as indefinições da integração entre o cuidado e a educação levam à suspensão de recursos destinados às creches através das SMAS; em muitos municípios $o$ atendimento restringe-se prioritariamente à faixa etária de cindo a seis anos; em decorrência de falta de financiamento próprio para educação infantil a oferta de período integral é reduzida; a ampliação do atendimento sofre redução ou paralisação. São desafios que precisam ser enfrentados.

A LDB determina a transferência das creches para o âmbito educacional e exige a formação em nível superior de todos os profissionais. Tais medidas têm criado impasses e distúrbios que redundam em maior discriminação: leigos são demitidos, há redução ou paralisação do atendimento, preconceitos relacionados às funções e equiparação de cargos, convênios diferenciados entre SMAS e SME dificultam a integração. Práticas centralizadas de aquisição de material prejudicam a disponibilidade e adequação dos recursos no cotidiano; projetos sobre a prática pedagógica definidos de modo exógeno, em desrespeito ao profissional como ator do processo; predomínio de concepções de educação infantil fragmentadas, voltada para a escolarização ou apenas para o cuidado; precariedade de infraestrutura dos equipamentos, especialmente das entidades conveniadas; complexidade e diversidade na estrutura, no funcionamento e no tamanho das redes que, se, em Limeira, conta com 13 creches, na cidade de São Paulo, ultrapassa 700 unidades. A formação profissional constitui a principal ação capaz de enfrentar a maioria dos problemas da educação infantil.

Outro desafio é a implementação do complexo e polissêmico conceito de qualidade na educação infantil (Dahberg, Oliveira-Formosinho \& Formosinho, 2001; Moss \& Pence, 1999). Quer se trate de produtos (leis e normas sobre a estrutura e funcionamento da educação infantil, financiamento, etc.), processos (formação profissional, elaboração de propostas pedagógicas, inovações, pesquisa, etc.) ou concepções, é necessário um esforço para que cada segmento da sociedade cumpra sua função para melhorar processos, produtos e concepções que beneficiem a educação de crianças pequenas.

Não se pode pensar em desenvolvimento integral da criança sem incorporar o corpo. A educação infantil esqueceu que o corpo é o primeiro brinquedo. Não só na perspectiva de jogo de exercício, mas de representação de brincadeiras pelo movimento. Rodar como pião, cantando parlendas e músicas 
que falam sobre a alegria de rodopiar, expressa 0 prazer anunciado por Caillois (1967), no ato da vertigem. Unir a representação pelo gesto à da palavra cantada e recriada é ser criança, é deixar que o corpo se una ao lúdico e expresse os códigos da cultura em que a criança vive.

Um dedo que se transforma em personagem da história, que encanta qualquer criança, inclusive no recinto frio e ameaçador do hospital, que a faz esquecer a dor física, a violência à que está submetida, quando é afastada de seus familiares, amigos, brinquedos, traz o equilíbrio necessário para superar as dificuldades (Lindquist, 1993). É como uma "resiliência" para a criança (Kotiarenco, 1997). Torna o hospital e as condições hospitalares mais humanas. Não anula a infância. Permite que a criança seja criança, não importa o lugar em que esteja.

O corpo carrega a dimensão de integrar emoções, contatos sociais e relações (Wallon, 1966). O cotidiano de nossas práticas tende a separar o corpo de outras dimensões. É mais uma vez a violência simbólica (Biarnès, 1999) de construções sociais que esquecem a criança, o brincar, o prazer, a emoção, a parceria, a socialização e a recriação.

A Educação Física, no processo de construção de seu campo disciplinar, prioriza a ginástica e o esporte. Despreza a singeleza da natureza que criou o ser humano dotado de dimensões que se integram. Separou o homem em biológico, social, emocional e cognitivo. Criou esferas de estimulação para cada dimensão e esqueceu-se de que o ser humano é o conjunto delas. A nova taxionomia criada pelas áreas do conhecimento desintegrou o ser humano, impediu o brincar, emoções que conduzem ações, possibilitam relações e representações.

O corpo se integra na representação e no brincar, quando o faz-de-conta acontece em ambiente dotado de materiais e brinquedos, similares ao ambiente natural em que vivem as crianças. Uma cozinha, na dimensão da criança, possibilita andar, abaixar, esticar, movimentos que se integram à representação de ser cozinheiro, dona de casa, mãe, que possibilitam a socialização, a exploração. Não é a ação que dirige a representação, mas a representação que dirige a ação (Vygotski, 1988, 1982). Nesse espaço, a criança se curva para pegar um bebê, fica de pé para preparar a comida no fogão, dá uma volta para chegar ao berço, anda em direção ao amigo que desempenha o papel de motorista. A integração entre o corpo, o movimento e os objetos chamados brinquedos ou brincadeiras que movimentam 0 corpo é fundamental para a educação da criança pequena.

No mundo das miniaturas se brinca sozinho, sentado, com pequenos brinquedos. Mesmo que a representação esteja presente, não ocorre a ampla motricidade, os amigos para dividir brincadeiras. $O$ brincar solitário explica-se pelo novo modo de vida da família que se reduz, às vezes, à mãe, que trabalha e deixa a criança, em recintos pequenos, com a TV ou com seus brinquedos.

Num mundo violento em que novas configurações inauguram o novo milênio, com o terrorismo, a intolerância, o radicalismo, é preciso recuperar as cem linguagens da criança (Edwards, Gandini \& Forman, 1999), lendas da Amazônia (Faria, 1999), os muiraquitãs, os contos e mitos indígenas, o "velho Chico" o rio da integração nacional, que corta inúmeros Estados, trazendo a mãe d'água, o nego do rio, o cachorro do mato, o barco fantasma, o boto cor de rosa que mergulha nas águas claras dos rios amazônicos e carrega moças bonitas para dentro do rio.

Nas cidades do interior, a mula sem cabeça assombrava crianças, nas noites escuras de Brodósqui, nas lembranças de Portinari. Nos tempos da escravidão, meninos de engenho, da Casa Grande, brincavam, com seus irmãos e primos, de ser dono de engenho de açúcar, de construir um capa-bode, uma engenhoca para obter o caldo da cana. As brincadeiras do moleque sapeca, o menino-diabo, que, na descrição de Machado de Assis, batia no lombo do negrinho da senzala, seu companheiro de brincadeira, com uma vara de laranjeira, transformando-o em burro de carga ou, ainda, o capitão do mato ou capitão do campo, o caçador de negros, o cangaceiro, com chapéu e espada formando o batalhão do sertão nordestino são as marcas do imaginário infantil, personagens construídas nos contextos sociais da escravidão, do canavial, do início da industrialização, compartilhadas pelo mundo infantil, na forma de faz-de-conta.

O brincar era possível nas ruas, quintais, nas casas espaçosas que abrigavam uma família ampliada com avós, tios, amigos. Nesse "locus", a socialização e o aprender novas modalidades de brincadeiras eram o ofício da criança. Construíam-se piões de madeira, cascas, sementes de frutas e legumes; bonecas de espigas de milho e palha, acompanhadas de histórias dos tempos passados. 
Hoje, os pais não têm tempo. Guardaram nas gavetas do passado seus sonhos, sua história, brinquedos e brincadeiras e compram brinquedos para os filhos. É a rotinização da infância (Barbosa, 2000) em ambientes fechados, em salas de aulas com crianças apenas da mesma idade, nos cursos extracurriculares que se multiplicam para o desespero dos pequenos. Tais práticas, homogeneizadoras, liberam os pais e ocupam a criança, eliminando o tempo da infância.

Fala-se da importância da infância, mas são poucos os projetos com sua participação. Os adultos falam pelas crianças, que não têm voz, não são ouvidas.

Com a urbanização, industrialização e novos modos de vida, esqueceu-se a criança, encurtou-se a infância, a criança tornou-se um precoce aprendiz.

Em 1840, Froebel (1913) introduziu o lúdico nos jardins de infância. Nas Cartas às Mães (Froebel, 1912), orientava-as para brincar com seus filhos, estimular a representação simbólica, utilizando músicas, danças, movimento e o corpo. Sua proposta incluía a formação das jardineiras, o uso de brinquedos (de construção) para ensinar números, formas, conceitos.

Ao propor movimentos associados à representação, o psicólogo da infância deixou seu legado à educação infantil (Kishimoto, 1996). Mas a apropriação de teorias nem sempre caminha conforme os pressupostos do criador. Da teoria froebeliana foram mais divulgados os dons que serviram para ensinar por meio dos jogos. É a pedagogia dos jogos dirigidos, que prevaleceu na expansão dos jogos froebelianos e conquistou o espaço da educação infantil. Nesse caminho, Dewey introduziu o faz-de-conta na escola, trouxe os brinquedos na dimensão da criança, evidenciou a importância da representação dos problemas da sociedade nas brincadeiras infantis. Outros, como Montessori, continuaram a enfatizar jogos para encaixar, seriar, somar... (Kishimoto, 1998). No longo caminho percorrido pela constituição do campo da educação infantil, entre a assistência e a educação, a maternagem e a profissionalização, a escolarização e a vivência de experiências significativas, o brincar foi sendo marginalizado.

A escola fechou as portas para a cultura, tirou as brincadeiras, privilegiou $\mathbf{0}$ conhecimento sistematizado (Bruner, 1996). A educação para o brincar deu lugar à educação pelo brincar e à educação para outras finalidades.

Surge a violência simbólica (Biarnés, 1997) na forma de organizar o ambiente da escola, com salas abarrotadas de mesas e cadeiras, no quadro para o reprodução da escrita, em armários que impedem a autonomia e a escolha de materiais, que fecham as portas para $o$ imaginário, na repetição de monótonos exercícios motores ou na proibição da motricidade inerente às crianças pequenas. Multiplicam-se atividades repetitivas e fragmentadas com materiais, como papel e lápis, que poucas oportunidades oferecem às crianças de se engajar na exploração de seu ambiente. Estruturas inadequadas não disponibilizam profissionais em tempo e em número suficientes para o desenvolvimento de propostas das crianças. À semelhança dos orfanatos e asilos (Foucault, 1977), a escola fechou as portas para a expressão e a exploração da criança.

O censo de educação infantil (2000) aponta a existência de brinquedos em $84 \%$ das escolas, jogos didáticos, em $74 \%$, material para expressão artística, em $62 \%$, sucata, $83 \%$ e livros de literatura em $58 \%$ dos estabelecimentos (INEP, Censo 2000).

Tais diagnósticos, tipo surveys, não explicitam a adequação dos materiais e brinquedos nem seus usos. Geralmente, mesmo disponíveis nas escolas, ficam guardados, são utilizados de vez em quando ou são insuficientes para o número de crianças ou inadequados para a faixa etária. Para Machado (2001) pesquisas similares indicam que os materiais tecnológicos encontram-se em quase todas as escolas paulistas, mas $54 \%$ estão sem condições de uso, a maioria não conhece os programas da TV Escola (66\%) e apenas 32\% conhecem algumas programações.

Kishimoto (1998), ao pesquisar os brinquedos e materiais pedagógicos na rede municipal de São Paulo, no período de 1996-1998, aponta a relevância da pesquisa quantitativa complementada pela qualitativa. Enquanto os dados quantitativos evidenciam a pouca disponibilidade de brinquedos de faz-de-conta, construção e socialização e um alto percentual de recursos que favorecem a escolarização, a pesquisa qualitativa indica que tais materiais, mesmo disponíveis, são pouco utilizados em decorrência de concepções de criança e de educação associados a fatores estruturais.

Em Braga, Portugal, uma criança de quatro anos dizia à professora que gostaria de brincar sem ter que planejar, executar e avaliar no momento dos pequenos grupos.

No bojo da questão está a concepção de brincar como ação livre, iniciada, motivada e mantida pela criança. Como admitir a descrição 
prévia de uma ação que nasce das motivações da criança, não tem rumo, não pode ser antecipada? $O$ High-Scope ${ }^{3}$ cria um ambiente propício ao lúdico, quando é usado conforme as intenções da criança, em um tempo e espaço que fazem parte do ato lúdico. Se o modelo obriga a planejar a atividade que a criança escolhe livremente, antes da ação de brincar, há uma incoerência que precisa ser explicitada. Descrever a atividade antes não é substituir o lúdico pelo não brincar? O lúdico é imprevisível. Os temas e processos do brincar nascem e se desenvolvem no contexto lúdico e mudam por razões que, às vezes, nem o sujeito que brinca pode explicar. Narrar o resultado da brincadeira é ato pedagógico relevante para a aquisição da oralidade, mas descrever o que se pretende fazer descontextualizado do processo de brincar é, em muitos casos, prender o lúdico ao quadro dirigido das práticas pedagógicas. A rotina do High-Scope ${ }^{4}$ de planejar, executar e rever opõese ao ato lúdico que prescinde da revisão. $O$ brincar se esgota no próprio processo de brincar. Por seu caráter improdutivo, não há um produto para ser avaliado. Seria mais coerente deixar a criança escolher a área, brincar no tempo de atividade livre, sem exigir explicações (Brougère ,1995; Caillois, 1967; Huizinga, 1951; Kishimoto, 1995).

Para Buges (2000), citando Foucault (1988), o currículo, em geral, é instrumento de poder sobre a criança. Já outras propostas como as escolas italianas, as do norte da Europa e os jardins de infância japoneses disponibilizam brinquedos e materiais para uso independente (Kishimoto, 1995, 1997, 1998). Cabe analisar se estruturas dirigidas, livres ou ambas possibilitam uma melhor organização das atividades infantis.

Pouco se sabe se o jogo livre ou a atividade dirigida contribui para a qualidade da educação infantil. A educação para o brincar $^{5}$ pelo brincar $^{6}$ e para outras finalidades ${ }^{7}$ é tema que exige pesquisa. Leavers (2000), propõe uma escala para avaliar o envolvimento da criança, incluindo o brincar, com 10 princípios ${ }^{8}$

1 repartir o espaço da classe em cantos atrativos;

2 controlar equipamento de cantos e substituir os materiais pouco interessantes pelos mais interessantes;

3 introduzir novos materiais e atividades nãoconvencionais;

4 observar as crianças, sondar seus interesses, conceber e oferecer atividades relacionadas;

5 sustentar as atividades por meio de impulsos estimulantes e intervenções enriquecedoras;
6 estimular a iniciativa das crianças e sustentá-la por meio de regras e acordos;

7 examinar sua relação com cada criança e a das crianças entre si e procurar melhorá-las;

8 oferecer atividades que auxiliem as crianças a explorarem o mundo dos sentimentos, valores $e$ experiências;

9 reconhecer as crianças que têm problemas socioemocionais e ajudar por meio de intervenções que resultem em seu bem-estar e

10 reconhecer as crianças que têm necessidades particulares no plano do desenvolvimento e ajudálas por meio de intervenções que visem aumentar sua implicação nos domínios ameaçados (Leavers, 2000, p.311).

Tais princípios focalizam espaços e materiais para brincar e podem dar ao profissional melhores condições para avaliar e decidir sobre alternativas que ofereçam equilíbrio entre a orientação e a livre ação da criança de acordo com suas possibilidades e necessidades.

O brincar é o caminho que possibilita a flexibilidade, a recriação, as relações e a comunicação entre os homens (Bateson, 1977).

Brincam apenas as pessoas que se comunicam, que decodificam a linguagem, os gestos, as significações de cada cultura. $\mathrm{O}$ autor aponta que os loucos não conseguem se comunicar por meio de brincadeiras. Na demência, as visões se misturam à realidade. A representação da perseguição leva o sujeito a pensar que está sendo perseguido. $O$ sujeito não discrimina o sonho da realidade, o imaginário do real. Não se pode misturar o real com o imaginário. Afirmar que os brinquedos de guerra podem tornar a criança violenta é considerar que a criança tem psicose, confunde o real e o imaginário. Se consideramos a educação como a busca de finalidade, pode-se admitir a interdição de brinquedos de guerra na educação das crianças pequenas assim como se escolhe uma religião, uma atividade ou curso de língua estrangeira. Não se trata de misturar a realidade com a fantasia.

Se a Constituição de 1988 e a Lei de Diretrizes e Bases da Educação Nacional de 1996 são marcos históricos, conceituais e simbólicos, por verem a criança de zero a seis anos como sujeito de direitos e proporem a igualdade de oportunidades para uma educação de qualidade, é preciso analisar como tais significados são transformados em ações. Subterfúgios retóricos criam instrumentos de poder sobre a criança como os currículos e orientações exógenos (Buges, 2000). Para ultrapassar posturas que não chegam a 
uma Pedagogia da Transformação, é preciso eliminar 0 isolamento, valorizar os saberes profissionais (Nóvoa, 1992), caminhar em direção às comunidades educativas (Machado, 1999), construir, em parceria com a universidade, os centros de formação, a escola, a família, a comunidade e as crianças, um processo de formação inicial que se integre à continuada, que melhore a qualidade da educação das crianças e de suas famílias (Oliveira-Formosinho \& Formosinho, 2001), superando os desencontros na formação dos profissionais de educação infantil (Kishimoto, 1999).

\section{NOTAS}

1. Conferência de abertura.

2. Na educação infantil o termo escolarização é utilizado como inadequação de práticas de leitura, escrita e cálculo, desrespeitando a aquisição de experiências significativas da criança.

3. É um modelo curricular para a infância que prioriza áreas do conhecimento e formas de organização da rotina. Ver Oliveira - Formosinho (1998) e Holmann \& Weikart (1997).

4. O High-Scope, embora com rotina e áreas fixas, distancia-se do modelo escolarizado.

5. Respeita-se a iniciativa e os interesses das crianças no processo de brincar.

6. O brinquedo é instrumento da educação. É um jogo educativo.

7. A educação infantil deve prever experiências estruturadas que possibilitem a aquisição de experiências significativas, mas que não podem ser classificadas como lúdicas.

8. Leavers (Bélgica) construiu uma escala de envolvimento com três níveis: nível 1: criança ausente, ação estereotipada e repetição de gestos elementares; nível 3: a criança tenta fazer uma construção, escutar uma história, mas não há sinais que mostram motivação, concentração; e nível 5: a criança está absorvida na atividade.

\section{REFERÊNCIAS BIBLIOGRÁFICAS}

BARBOSA, M.C. Fragmentos sobre a rotinização da infância. Revista Educação \& Sociedade, v.25, n.1 p.93-114, 2000.

BATESON, G. Vers une écologie de l'esprit. Trad. Ferial Drosso, Laurencine Lot et Eugène Simion. Paris, Éditions du Seuil,1977. v.1.
BECCHI, E.; JULIA, D. Histoire de l'enfance en occident de I'antiquité au XVIIe. siècle. Paris, Éditions du Seuil, 1998.

BIARNĖS, J. Universalité, diversité, sujet dans l'espace pédagogique. Paris, Harmattan, 1999.

BRONFENBRENNER, U. A ecologia do desenvolvimento humano: experimentos naturais e planejados. Porto Alegre, Artes Médicas, 1996.

BROUGẺRE, G. Jeu et éducation. Paris, Harmattan, 1995.

BRUNER, J.S. L'éducation entrée dans la culture: les problèmes de l'école à la lumière de la psychologie culturelle. Trad. Yves Bonin. Paris, Retz, 1996.

BUGES, M.I.E. O fio e a trama: as crianças nas malhas do poder. Educação \& Realidade, v.25, n.1, p.2544, 2000.

CADWELL, L.B. Bringing reggio Emilia home. Columbia, Columbia University/Teachers College, 1999.

CAILlOIS, R. Les jeux et les hommes. Paris, Gallimard, 1967.

DAHBERG, G.; MOSS, P.; PENCE, A. Beyond quality in early childhood education and care. London, Routledge Palmer, 1999.

EDWARDS, C.; GANDINI, L.; FORMAM, G. As cem linguagens da criança. São Paulo, Artes Médicas, 1999.

FARIA, A.L.G. Educação pré-escolar e cultura: para uma pedagogia da educação infantil. São Paulo, Cortez,1999.

FORQUIN, J.-C. École et culture: le point de vue des sociologues britanniques. 2.ed. Paris, Le Boeck \& Larcier, 1996.

FOUCAULT, M. História da sexualidade 1: a vontade de saber. Trad. de Maria Thereza da Costa Albuquerque e J.A. Guilhon Albuquerque. 12.ed. Rio de janeiro, Edições GRAAL, 1988.

FROEBEL, F. La educación del hombre. Trad. de Luis de. Daniel Jorro Zulueta. S.l., s.ed., 1913.

Letters to a mother on the philosophy of Froebel. New York, Appleton, 1912. (10. versão em 1899). (International Education Series, v.45).

HADDAD, L. A creche em busca de identidade. São Paulo, Loyola, 1991.

HOHMANN, M.; WEIKART, D.P Educar a criança. Lisboa, Fundação Calouste Gulbenkian, 1997.

HUIZINGA, J. Homo ludens: essais sur la fonction sociale du jeu. Paris, Gallimard, 1951.

KISHIMOTO, T.M. Brinquedo e brincadeira na educação infantil japonesa: proposta curricular dos anos 90 . Educação \& Sociedade, v.18, n.60, p.6488, 1997

Froebel e a concepção de jogo infantil. Revista da Faculdade de Educação, v.22, n.1, p.145-68, 1996.

A história da pré-escola em São Paulo. São Paulo, Loyola, 1988.

Jogo, brinquedo, brincadeira e educação. São Paulo, Cortez, 1995. 
O primeiro jardim de infância público no Estado de São Paulo. Educação \& Sociedade, v.17, n.56, p.452-75, 1996.

. Relatório final da pesquisa. São Paulo, FAPESP, 1998.

Salas de aula de escolas infantis: domínio da fila, tempo de espera e falta de autonomia da criança. Nuances: Revista do Curso de Pedagogia, Presidente Prudente, v.5, n.4, p.1-7, 1999.

KOTIARENCO, M.A.. El juego como posibilidad de refuerzo a la resiliência. In: SANTOS, S.M.P., org. Brinquedoteca: o lúdico em diferentes contextos. Petrópolis, Vozes, 1997. p.41-3.

LEAVERS, F. L'éducation expérientielle: l'implication de l'enfant, un critère de qualité. In: RAYNA, S.; BROUGÈRE, G., coords. Traditions et innovations dans l'éducation prescolaire: perspectives internationales. Paris, Institut National de Recherche Pedagogique, 2000. p.293-321.

LINDQUIST, I. A criança no hospital: terapia pelo brinquedo. São Paulo, Scritta, 1993.

MACHADO, E.V. O vídeo como mediador da comunicação escolar. São Paulo, 2001. Tese (Doutorado) Faculdade de Educação da Universidade de São Paulo.

MACHADO, J., coord. Autonomia, flexibilidade e associação. Braga, Centro de Formação de Associação de Escolas Braga/Sul, 1999. [Actas do Seminário realizado em 9 de julho de 1999 , no Instituto de Estudos da Criança da Universidade do Minho].
NÓVOA, A., org. As organizações escolares em análise. Lisboa, Dom Quixote, 1992.

OLIVEIRA-FORMOSINHO J., org. Modelos curriculares para a educação de infância. Porto, Editora Porto, 1998.

OLIVEIRA-FORMOSINHO ，J.; FORMOSINHO, J., orgs. Associação criança: um contexto de formação em contexto. Braga, Livraria Minho, 2001.

PASCAL, C.; BERTRAM, T.; GASPER, M.; MOULD, C.; RAMSDEN, F.; SAUNDER, M. Research to inform the evaluation of the early excellence centres: pilot programme: Centre for Research in Early Childhood. Worcester, University College Worcester, 1999.

PERRENOUD, P. Avaliação da excelência à regulação das aprendizagens: entre duas lógicas. Porto Alegre, Artes Médicas, 1999.

PINTO, M.; SARMENTO, M.J. As crianças contextos e identidades. Minho, Universidade do Minho/Centro de Estudos de Criança, 1997.

RAYNA, S.; BROUGĖRE, G., coords. Traditions et innovations dans l'éducation prescolaire: perspectives internationales. Paris, Institut National de Recherche Pedagogique, 2000.

VYGOTSKI, L.S. A função social da mente. 2.ed. São Paulo, Martins Fontes, 1988.

La imaginación y el arte en la infancia. Madrid, Akal, 1982 WALLON, H. Do acto ao pensamento. Lisboa, Portugalia, 1966. 